\title{
Stimulation of Bile Duct Epithelial Secretion by Glybenclamide in Normal and Cholestatic Rat Liver
}

\author{
Michael H. Nathanson, Angela D. Burgstahler, Albert Mennone, Jonathan A. Dranoff, and Laura Rios-Velez \\ Liver Study Unit and Department of Cell Biology, Yale University School of Medicine, New Haven, Connecticut 06520
}

\begin{abstract}
Cholestasis is a cardinal complication of liver disease, but most treatments are merely supportive. Here we report that the sulfonylurea glybenclamide potently stimulates bile flow and bicarbonate excretion in the isolated perfused rat liver. Video-microscopic studies of isolated hepatocyte couplets and isolated bile duct segments show that this stimulatory effect occurs at the level of the bile duct epithelium, rather than through hepatocytes. Measurements of cAMP, cytosolic $\mathrm{pH}$, and $\mathrm{Ca}^{2+}$ in isolated bile duct cells suggest that glybenclamide directly activates $\mathrm{Na}^{+}-\mathrm{K}^{+}-2 \mathrm{Cl}^{-}$cotransport, rather than other transporters or conventional second-messenger systems that link to secretory pathways in these cells. Finally, studies in livers from rats with endotoxin- or estrogen-induced cholestasis show that glybenclamide retains its stimulatory effects on bile flow and bicarbonate excretion even under these conditions. These findings suggest that bile duct epithelia may represent an important new therapeutic target for treatment of cholestatic disorders. (J. Clin. Invest. 1998. 101:2665-2676.) Key words: cholangiocyte • secretion • cholestasis • ion transport • video microscopy
\end{abstract}

\section{Introduction}

Cholestasis is one of the major manifestations of liver disease. Chronic cholestasis leads not only to impaired liver function and cirrhosis, but to systemic complications such as vitamin deficiencies, bone disease, steatorrhea, and pruritus (1). Currently, most pediatric liver transplants and nearly $20 \%$ of all liver transplants in the United States are performed for cholestatic disorders and their complications (United Network of Organ Sharing statistics). A number of supportive measures are available to treat the symptoms and complications of chronic cholestasis $(1,2)$, but the only medical treatment that may improve the clinical course of these disorders is ursodiol. This hydrophilic bile acid improves biochemical indices of cholestasis and may improve outcome in patients with primary biliary cirrhosis (3), sclerosing cholangitis (4), and cystic fibrosis (5). However, months to years of treatment are required to detect a beneficial effect in patients, so improved forms of treatment are desirable.

Address correspondence to Dr. Michael H. Nathanson, Liver Study Unit, Room 1080 LMP, Yale University School of Medicine, $333 \mathrm{Ce}-$ dar Street, New Haven, CT 06520. Phone: 203-785-4138; FAX: 203785-4306; E-mail: michael.nathanson@yale.edu

Received for publication 16 January 1998 and accepted in revised form 7 April 1998.

J. Clin. Invest.

(C) The American Society for Clinical Investigation, Inc. 0021-9738/98/06/2665/12 \$2.00

Volume 101, Number 12, June 1998, 2665-2676

http://www.jci.org
Cholestatic disorders often are the result of dysfunction of bile duct cells, the epithelia that line the biliary tree (6). Therefore, a rational approach to treat cholestasis may be to stimulate ductular secretion. Treatment has not been directed specifically at bile duct cells, though, in part because knowledge about these cells has been limited. However, there have been major recent advances in our understanding of bile duct cell biology and physiology $(6,7)$. Here we take advantage of these advances to define an approach to specifically increase secretion by bile duct epithelia, and to demonstrate the potential utility of this approach for the treatment of cholestatic disorders.

\section{Methods}

Animals and materials. Male 180-250-g Sprague-Dawley rats were used for all experiments. Glybenclamide, ATP, LPS from Salmonella typhimurium, $17 \alpha$-ethynyl estradiol, forskolin, secretin, and dibutyryl cAMP were obtained from Sigma Chemical Co. (St. Louis, MO), and fluo-3/acetoxymethyl ester (fluo-3/AM) ${ }^{1}$ and $2^{\prime}, 7^{\prime}$-bis-(2-carboxyethyl)-5-(and 6)-carboxy fluorescein/acetoxymethyl ester (BCECF/ AM) were obtained from Molecular Probes (Eugene, OR). All other chemicals were of the highest quality commercially available.

Isolated perfused rat liver studies. Liver perfusions were performed in the Perfusion Core Facility of the Yale Liver Center as described previously $(8,9)$. Rats were anesthetized with pentobarbital ( $50 \mathrm{mg} / \mathrm{kg}$ body wt) and the bile duct was cannulated. The portal vein was then cannulated with an intravenous catheter and the liver was perfused at $25 \mathrm{ml} / \mathrm{min}$ with oxygenated KRB buffer containing heparin. After cannulation of the inferior vena cava, the liver was transferred into a temperature-controlled perfusion chamber and perfused in a nonrecirculating (single-pass) fashion at $40 \mathrm{ml} / \mathrm{min}$ with $\mathrm{KRB}$ buffer. The buffer was gassed continuously with a mixture of $95 \% \mathrm{O}_{2} /$ $5 \% \mathrm{CO}_{2}$ and maintained at $37^{\circ} \mathrm{C}$ by monitoring the temperature with a thermister probe inserted between the lobes of the liver. Bile flow was measured gravimetrically in pretared tubes and perfusion pressure was monitored continuously. Biliary $\mathrm{HCO}_{3}^{-}$and $\mathrm{pH}$ were measured using a blood gas analyzer, and bile samples obtained for this purpose were collected under oil and maintained on ice until they were analyzed. The viability of each liver preparation was ascertained by monitoring perfusion pressure and $\mathrm{O}_{2}$ consumption during the course of the experiment, and by determining trypan blue distribution upon completion $(8,9)$.

Preparation of isolated rat bile duct units and isolated rat hepatocyte couplets. Isolated bile duct units from small interlobular ducts were prepared in the Cell Isolation Core Facility of the Yale Liver Center as described previously $(10,11)$. Rats were anesthetized with pentobarbital ( $50 \mathrm{mg} / \mathrm{kg}$ body wt), their portal veins were cannulated and their livers were perfused first with Hanks A medium, and then with Hanks B medium containing collagenase and trypsin inhibitor. Portal tissue residue was mechanically separated from the parenchyma, minced, and digested. The resulting suspension was passed

1. Abbreviations used in this paper: $\mathrm{BCECF} / \mathrm{AM}, 2^{\prime}, 7^{\prime}$-bis-(2-carboxyethyl)-5-(and 6)-carboxy fluorescein/acetoxymethyl ester; CFTR, cystic fibrosis transmembrane conductance regulator; DIDS, 4,4'Diisothiocyanatostilbene-2,2'-disulfonic acid; fluo-3/AM, fluo-3/acetoxymethyl ester. 
through nylon mesh filters and fragments between 30 and $100 \mu \mathrm{m}$ diam were plated onto Matrigel-coated coverslip fragments and incubated at $37^{\circ} \mathrm{C}$ in a $95 \% \mathrm{O}_{2} / 5 \% \mathrm{CO}_{2}$ atmosphere with $\alpha$-MEM supplemented with insulin, FCS, L-glutamine, gentamycin, penicillin, and streptomycin. Bile duct units isolated in this fashion stain positively for the biliary epithelial markers $\gamma$-glutamyl transpeptidase and cytokeratin 19 and 7, and negatively for markers of other types of liver cells $(10,11)$. Experiments were performed $24-48 \mathrm{~h}$ after plating, using only those bile duct units with visible, sealed lumens (10).

Isolated rat hepatocyte couplets also were prepared in the Cell Isolation Core Facility of the Yale Liver Center as described previously (12-14). Rat livers were perfused with collagenase-containing medium, and then excised, minced, and passed through serial nylon mesh filters. The resultant cells were washed. These cells were suspended in Leibovitz L-15 medium containing $10 \%$ FCS, 50 U penicillin, and $50 \mathrm{mg}$ streptomycin $/ \mathrm{ml}$; they were then plated onto glass coverslips. Cells were incubated at $37^{\circ} \mathrm{C}$ and used $2-6 \mathrm{~h}$ after plating. Approximately $20 \%$ of hepatocytes prepared in this fashion were in couplets. The viability of hepatocytes by trypan blue exclusion measured $2 \mathrm{~h}$ after plating exceeded $90 \%$.

Secretion measurements in isolated bile ductule units and isolated hepatocyte couplets. Secretion in isolated bile duct units and in isolated rat hepatocyte couplets was measured by video microscopic optical planimetry as described previously $(10,11,13,14)$. Bile duct units or hepatocyte couplets were isolated and incubated at $37^{\circ} \mathrm{C}$ as described above; then the coverslip fragments containing the cells were transferred to a lucite chamber and perfused at $37^{\circ} \mathrm{C}$ with $1 \mathrm{ml} /$ min KRB buffer, or with a $\mathrm{HCO}_{3}^{-}$-free Hepes-based buffer in selected experiments. The chamber was placed on the stage of an inverted microscope (IM35; Carl Zeiss, Inc., Thornwood, NY) and cells were observed through a $63 \times$ objective lens. Nomarski optics were used to obtain a shallow $(0.25-0.3 \mu \mathrm{m})$ depth of focus, and the cells were imaged with a video camera (Dage-MTI series 68; Dage-MTI, Michigan City, IN) in the plane of focus in which the diameters of their enclosed lumens appeared largest $(10,14)$. Images were recorded on an optical disc using an optical memory disc recorder (TQ-2026F; Panasonic, Osaka, Japan), and luminal areas were determined from the recorded images using NIH Image Software (NIH, Bethesda, MD). Bile duct units were examined for 5 min under control conditions, and then for an additional $30 \mathrm{~min}$ in the presence of 100 $\mu \mathrm{M}$ glybenclamide, $50 \mu \mathrm{M}$ dibutyryl cAMP, or no stimulus. Images were obtained every 5 min throughout. Hepatocyte couplets were examined for $5 \mathrm{~min}$ under control conditions, and then for an additional $10 \mathrm{~min}$ in the presence of $100 \mu \mathrm{M}$ glybenclamide, $50 \mu \mathrm{M}$ dibutyryl cAMP, or no stimulus. Images were obtained every 2 min throughout. To account for differences in size among different bile duct units or couplets, each luminal area was normalized by its initial value (10). An increase in luminal area over time was taken as an index of secretion.

pH measurements in bile duct units. Cytosolic $\mathrm{pH}$ was measured in individual bile duct cells within isolated bile duct units using ratio microspectrofluorimetry as described previously $(10,15)$. Cells were isolated and prepared as described above, then loaded with $12 \mu \mathrm{M}$ BCECF/AM. Coverslips containing the cells were transferred to a chamber on the stage of a microscope (Axiovert 100TV; Carl Zeiss, Inc.), perifused at $37^{\circ} \mathrm{C}$ with $\mathrm{KRB}$ medium, and excited by a mercury arc lamp at 440 and $495 \mathrm{~nm}$. Images were observed at $510 \mathrm{~nm}$ using a Cohu CCD camera (San Diego, CA), ratioed on line, and recorded at a rate of two to six images per minute. Cells were transiently stimulated with $100 \mu \mathrm{M}$ glybenclamide in the presence or absence of amiloride, 4,4'-Diisothiocyanatostilbene-2,2'-disulfonic acid (DIDS), or bumetanide as described in Results; then, calibration measurements were made for each cell by changing the ambient $\mathrm{pH}$ in the presence of the $\mathrm{H}^{+}$ionophore nigericin $(12 \mu \mathrm{M})$. Cytosolic $\mathrm{pH}$ was calculated from the ratio measurements using the nigericin calibration curves as described previously $(10,15)$, and the rate of change of cytosolic $\mathrm{pH}$ $(d \mathrm{pH} / d \mathrm{t})$ during the initial phase of glybenclamide addition or withdrawal was calculated from these measurements by linear regression. The corresponding value for the proton flux $\mathrm{JH}^{+}$for each maneuver was calculated as $\left(\beta_{\text {total }}\right) \times(d \mathrm{pH} / d t)$, where $\beta_{\text {total }}=\beta_{\mathrm{i}}+2.303 \times$ $\left[\mathrm{HCO}_{3}^{-}\right]_{\mathrm{i}}, \beta_{\mathrm{i}}$ is the intrinsic buffering power at the intracellular $\mathrm{pH}$ at which the particular measurement was made (as has been reported previously for isolated bile duct units [16]), and the intracellular bicarbonate concentration $\left[\mathrm{HCO}_{3}^{-}\right]_{\mathrm{i}}$ was calculated from the Henderson-Hasselbach equation. Comparison of $\mathrm{JH}^{+}$among groups is more reliable than comparison of $d \mathrm{pH} / d t$, since the former is linearly rather than exponentially related to cytosolic $\mathrm{pH}$.

Measurements of $\mathrm{Ca}^{2+}$ and cAMP in bile duct units. $\mathrm{Ca}_{\mathrm{i}}^{2+}$ was measured in bile duct units using confocal video microscopy as described previously (11). Bile duct units were isolated and prepared as described above, then loaded with $6 \mu \mathrm{M}$ fluo-3/AM (11). Coverslips containing the cells were transferred to a chamber on the stage of a microscope (Axiovert; Carl Zeiss, Inc.), perifused at $37^{\circ} \mathrm{C}$ with a Hepes-buffered solution and observed using a confocal imaging system (MRC-600; Bio-Rad Laboratories, Richmond, CA) (11). Images were obtained at a rate of $1 \mathrm{~s}^{-1}$ using a $63 \times$ objective (spatial resolution, $0.26 \mu \mathrm{m} / \mathrm{pixel}$ ) and recorded using an optical memory disk recorder (TQ3031F; Panasonic). Each bile duct unit was examined first under control conditions, then in the presence of $100 \mu \mathrm{M}$ glybenclamide, followed by $10 \mu \mathrm{M}$ ATP, which is a known $\mathrm{Ca}_{\mathrm{i}}^{2+}$ agonist for these cells (11). Increases in $\mathrm{Ca}_{\mathrm{i}}^{2+}$ in cells within bile duct units were detected by measuring increases in fluorescence intensity (11).

cAMP was measured in populations of single bile duct cells, which were isolated in a similar fashion to bile duct units as described previously (16). A RIA kit was used (Amersham Corp., Arlington Heights, IL), and cells were examined after stimulation for 5 min with either $100 \mu \mathrm{M}$ glybenclamide, $100 \mathrm{nM}$ secretin, or $100 \mu \mathrm{M}$ forskolin. cAMP also was measured in a separate, unstimulated group. Measurements for each group were made in quintuplicate.

Animal models of cholestasis. Animal models of the cholestasis of sepsis and of drug-induced cholestasis were examined. Cholestasis of sepsis was induced by intraperitoneal injection of LPS from $1 \mathrm{mg} /$ $\mathrm{kg}$ S. typhimurium $16 \mathrm{~h}$ before liver isolation and perfusion (17). Drug-induced cholestasis was induced by subcutaneous injection of 5 $\mathrm{mg} / \mathrm{kg} 17 \alpha$-ethynyl estradiol daily for the $5 \mathrm{~d}$ before study (18).

Statistics and data analysis. Given the wide variability seen among cells in primary culture, treatment groups were compared only with control groups isolated from the same liver preparations. Values listed are mean \pm SEM, except where otherwise noted. Statistical comparisons were made using Student's $t$ test, or else using ANOVA with post-tests or Hotelling's $T^{2}$ test where appropriate; $P$ values $<$ 0.05 were taken as significant.

\section{Results}

Glybenclamide stimulates bile flow and biliary bicarbonate excretion. The effects of glybenclamide on bile flow were examined in the isolated perfused rat liver, an experimental system that allows liver function and bile secretion to be investigated independent of systemic or humoral effects (8). Glybenclamide increased bile flow potently and in a dose-dependent fashion, with a $K_{\mathrm{d}}$ of $9.5 \pm 3.2 \mu \mathrm{M}$. Glybenclamide doubled bile flow at a concentration of $100 \mu \mathrm{M}$, when it reached its maximal effect (Fig. 1, $A$ and $B$ ). This increase in bile flow was reversible; by $20 \mathrm{~min}$ after cessation of glybenclamide, the flow rate in livers treated with $100 \mu \mathrm{M}$ glybenclamide was no longer significantly higher than in untreated livers, and by $60 \mathrm{~min}$ after glybenclamide was withdrawn the flow rate in glybenclamidetreated livers was identical to that in untreated livers (1.12 \pm 0.08 and $1.14 \pm 0.11 \mu \mathrm{l} / \mathrm{g}$ liver/min, respectively; $n=3$ in each group). Livers were perfused without bile acids in the perfusate, so these findings reflect the effects of glybenclamide on bile acid-independent bile flow, which is responsible for approximately half of total bile flow under normal conditions 

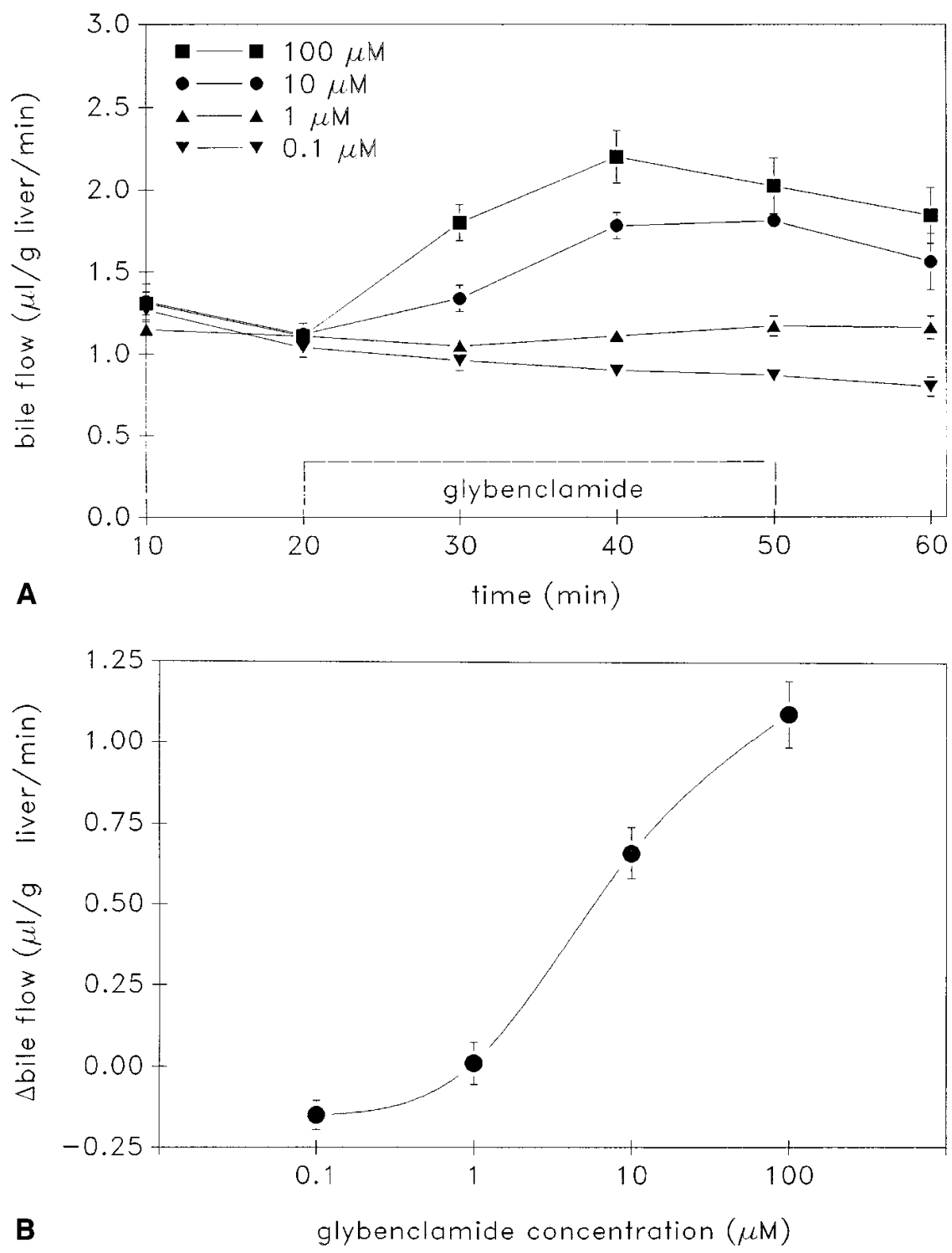

Figure 1. Glybenclamide stimulates bile flow in the isolated perfused rat liver. $(A)$ Pattern of glybenclamide-induced bile flow over time. Glybenclamide induces a rapid, dose-dependent increase in bile flow that slowly but completely reverses when the drug is withdrawn (see text). Values are mean $\pm \operatorname{SEM}(n=4-5$ livers for each concentration). ( $B)$ Doseresponse relationship. Shown are increases in bile flow relative to baseline, measured $20 \mathrm{~min}$ after initiation of glybenclamide administration. Note that basal bile flow rates are $\sim 1 \mu \mathrm{l} /$ $\mathrm{min} / \mathrm{g}$ liver (Fig. $1 A$ ), so that maximal stimulation $(100 \mu \mathrm{M})$ represents $\sim 100 \%$ increase in bile flow.
(19). The two major determinants of the bile acid-independent fraction of bile flow are $\mathrm{HCO}_{3}^{-}$and glutathione (20). Therefore, we measured $\mathrm{HCO}_{3}^{-}$and total glutathione in bile from livers treated with glybenclamide. Glybenclamide increased both biliary $\mathrm{HCO}_{3}^{-}$concentration and output, and in fact there was a strong linear correlation between biliary $\mathrm{HCO}_{3}^{-}$ concentration and bile flow in livers treated with 1-100 $\mu \mathrm{M}$ glybenclamide (Fig. $2 \mathrm{~A}$ ). In contrast, there was no such relationship between biliary glutathione concentration and bile flow in livers treated with glybenclamide (Fig. $2 B$ ). Thus, glybenclamide-induced biliary $\mathrm{HCO}_{3}^{-}$excretion appears to serve as a major driving force for the glybenclamide-induced choleresis.

Glybenclamide stimulates secretion by bile duct epithelia rather than by hepatocytes. Both hepatocytes and bile duct epithelia may contribute to the net secretion of bile $(6,20)$. To determine whether glybenclamide acts at the level of the hepatocyte or the bile duct epithelium, the effects of glybenclamide on secretion were examined in isolated rat hepatocyte couplets (Fig. $3 A$ ) and isolated bile duct units (Fig. $3 B$ ). Isolated rat hepatocyte couplets are freshly isolated pairs of hepatocytes, which retain structural and functional polarity and continue to secrete canalicular bile into the space they enclose (12). The rate of bile secretion by hepatocyte couplets can be quantified by measuring the change in volume of their enclosed canalicular space over time $(13,14)$. Similarly, bile duct units are freshly isolated segments of bile duct cells that retain structural and functional polarity. The ends of the segments seal in shortterm culture, so ductular secretion can be quantified by measuring the change in volume of this enclosed space over time $(10,11) .100 \mu \mathrm{M}$ glybenclamide did not increase canalicular volume over time in isolated rat hepatocyte couplets, while 50 $\mu \mathrm{M}$ dibutyryl cAMP increased volume by $29 \%(P<0.0001)$ over the same time interval (Fig. $3 C$ ). In isolated bile duct units, in contrast, $100 \mu \mathrm{M}$ glybenclamide increased ductular volume by $35 \%$ ( $P<0.005$ relative to baseline $)$, which is not different from the increase in volume over time induced by $50 \mu \mathrm{M}$ dibutyryl cAMP but is significantly $(P<0.03)$ greater than the secretory rate in control (unstimulated) bile duct units (Fig. $3 \mathrm{D}$ ). Dibutyryl cAMP was used as a positive 

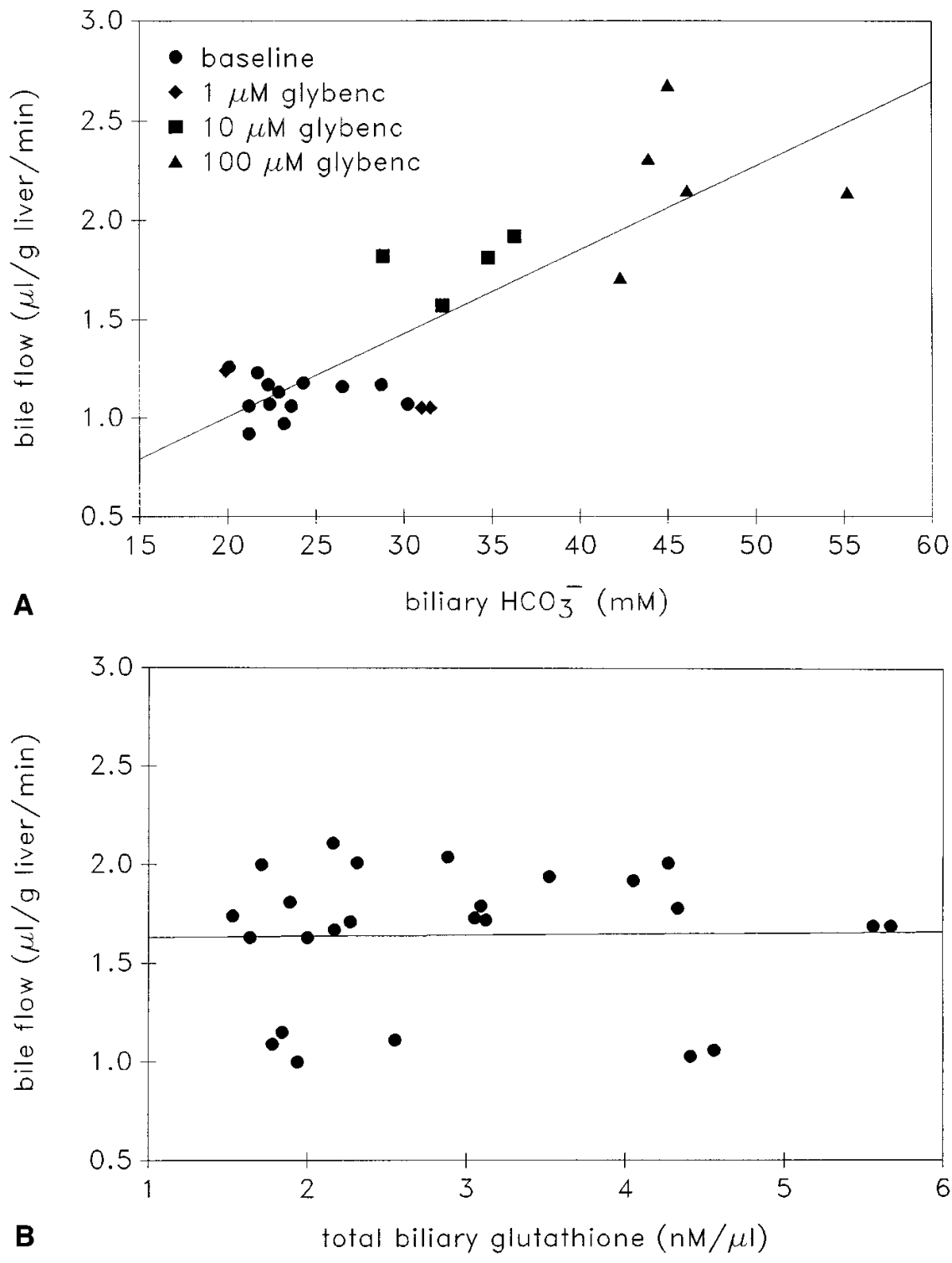

Figure 2. Glybenclamide stimulates secretion of $\mathrm{HCO}_{3}^{-}$but not glutathione in the isolated perfused rat liver. $(A)$ Glybenclamide increases biliary $\mathrm{HCO}_{3}^{-}$concentration in direct relation to increased bile flow. $\mathrm{HCO}_{3}^{-}$concentration was measured in bile samples collected during infusion with 1-100 $\mu \mathrm{M}$ glybenclamide. Line shown represents the linear regression curve for the data $(r=0.839 ; P<0.00001)$. (B) Glybenclamide does not increase glutathione concentration in bile. Total biliary glutathione was measured before and during infusion with 100 $\mu \mathrm{M}$ glybenclamide in five livers. Line shown represents the linear regression curve for the data $(r=0.02 ; P>0.4)$.

control for both isolated hepatocyte couplets and bile duct units since cAMP stimulates secretion in both hepatocytes $(20,21)$ and bile duct epithelial cells $(6,7)$. These findings demonstrate that glybenclamide increases bile flow by stimulating secretion at the level of the bile duct cell rather than the hepatocyte.

Mechanism of action of glybenclamide. A number of second messenger-activated channels and ion transporters may contribute to secretion by bile duct epithelia. Both the cAMPactivated cystic fibrosis transmembrane conductance regulator (CFTR) $\mathrm{Cl}^{-}$channel (22) and a separate $\mathrm{Ca}^{2+}$-gated $\mathrm{Cl}^{-}$channel $(23,24)$ are on the apical membrane of bile duct cells and play a direct role in increasing ductular secretion (7). Bile duct cells also possess an apical $\mathrm{Cl}^{-}-\mathrm{HCO}_{3}^{-}$exchanger that alkalinizes bile in response to $\mathrm{Cl}^{-}$secretion $(7,15,25)$, a basolateral $\mathrm{Na}^{+}-\mathrm{H}^{+}$exchanger responsible for recovery from the acid load associated with $\mathrm{HCO}_{3}^{-}$excretion $(7,15)$, a basolateral electrogenic $\mathrm{Na}^{+}-\mathrm{HCO}_{3}^{-}$cotransporter that provides the alkaline load to drive the $\mathrm{Cl}^{-}-\mathrm{HCO}_{3}^{-}$exchanger $(7,15)$, and a basolateral $\mathrm{Na}^{+}-\mathrm{K}^{+}-2 \mathrm{Cl}^{-}$cotransporter responsible for the
$\mathrm{Cl}^{-}$loading that drives apical $\mathrm{Cl}^{-}$secretion $(26,27)$. We systematically investigated the potential role of each of these channels and transporters in glybenclamide-induced ductular secretion. Since the best characterized stimulus for ductular secretion is cAMP $(6,7)$, we determined the effects of glybenclamide on cellular cAMP levels (Fig. $4 A$ ). Glybenclamide did not increase cAMP relative to baseline levels, even though significant increases occurred in response to stimulation with secretin, which is the physiologic activator of adenylyl cyclase, CFTR in these cells $(6,7)$, and forskolin. Since glybenclamide stimulates insulin secretion in pancreatic $\beta$ cells, its therapeutic target in diabetes, by increasing $\mathrm{Ca}_{\mathrm{i}}^{2+}(28,29)$, and since increases in $\mathrm{Ca}_{\mathrm{i}}^{2+}$ may stimulate secretion in bile duct cells as well $(16,24)$, we examined the effects of glybenclamide on bile duct cell $\mathrm{Ca}_{\mathrm{i}}^{2+}$ by confocal microscopy (Fig. $4 \mathrm{~B}$ ). Glybenclamide did not increase $\mathrm{Ca}_{\mathrm{i}}^{2+}$ in any of the cells in 13 isolated bile duct units, even though subsequent stimulation with the bile duct cell $\mathrm{Ca}_{\mathrm{i}}^{2+}$ agonist ATP (11) increased $\mathrm{Ca}_{\mathrm{i}}^{2+}$ in these cells in each case. We also examined this potential mechanism 

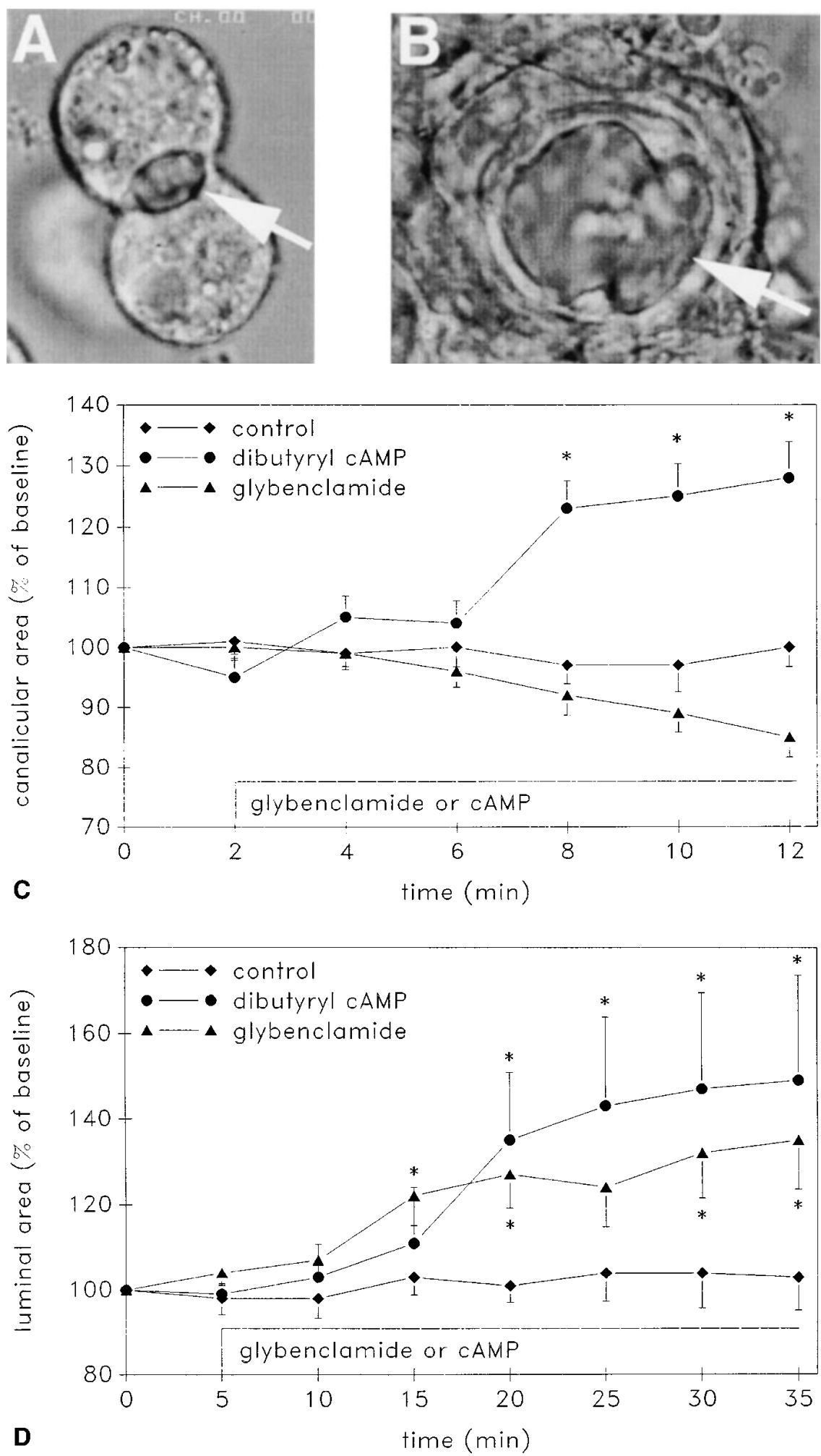

Figure 3. Glybenclamide stimulates secretion at the level of the bile duct epithelium. $(A)$ Nomarski image of an isolated rat hepatocyte couplet. The canalicular space enclosed by the two hepatocytes is indicated (arrow). Canalicular bile secretion by the couplets was determined by serial measurement of the cross-sectional area of this space over time $(13,14)$. $(B)$ Nomarski image of an isolated bile duct unit. The luminal space enclosed by the bile duct cells is indicated (arrow). Ductular secretion was determined by serial measurement of the cross-sectional area of this space over time (10, 11). (C) $100 \mu \mathrm{M}$ glybenclamide does not stimulate secretion in isolated rat hepatocyte couplets. In contrast, a significant increase in canalicular area over time $(* P<0.0001)$, relative to unstimulated (control) couplets, was observed in couplets treated with $50 \mu \mathrm{M}$ dibutyryl cAMP. Values represent mean \pm SEM of $n=27$ control couplets, $n=36$ glybenclamidetreated couplets, and $n=27$ couplets treated with the cAMP analog. $(D)$ Glybenclamide stimulates secretion in isolated bile duct units. Unlike in hepatocytes, $100 \mu \mathrm{M}$ glybenclamide and $50 \mu \mathrm{M}$ dibutyryl cAMP induced a similar increase in luminal area over time. Both increases are significantly greater than was seen in unstimulated (control) duct units $(* P<$ 0.05 ). Values represent mean \pm SEM of $n=$ 13 control duct units, $n=20$ glybenclamidetreated units, and $n=6$ units treated with the cAMP analog.

of action of glybenclamide in another way. Glybenclamide increases $\mathrm{Ca}_{i}^{2+}$ in $\beta$ cells by inhibiting $\mathrm{K}^{+}$channels, which then depolarizes these cells and triggers voltage-operated $\mathrm{Ca}^{2+}$ channels (29). Since bile duct cells also possess $\mathrm{K}^{+}$channels (30), we examined whether depolarization of these cells by high- $\mathrm{K}^{+}$medium would stimulate secretion. Incubation with medium containing high $(40 \mathrm{mM}) \mathrm{K}^{+}$had no effect on luminal volume in isolated bile duct units (Fig. 5). Together, these findings demonstrate that glybenclamide does not activate either of the second-messenger systems in bile duct cells that stimulate secretion in this type of cell, which in turn suggests that glybenclamide may instead directly activate one of the transporters that promote secretion.

We investigated the effects of glybenclamide on $\mathrm{Na}^{+}-\mathrm{H}^{+}$ 

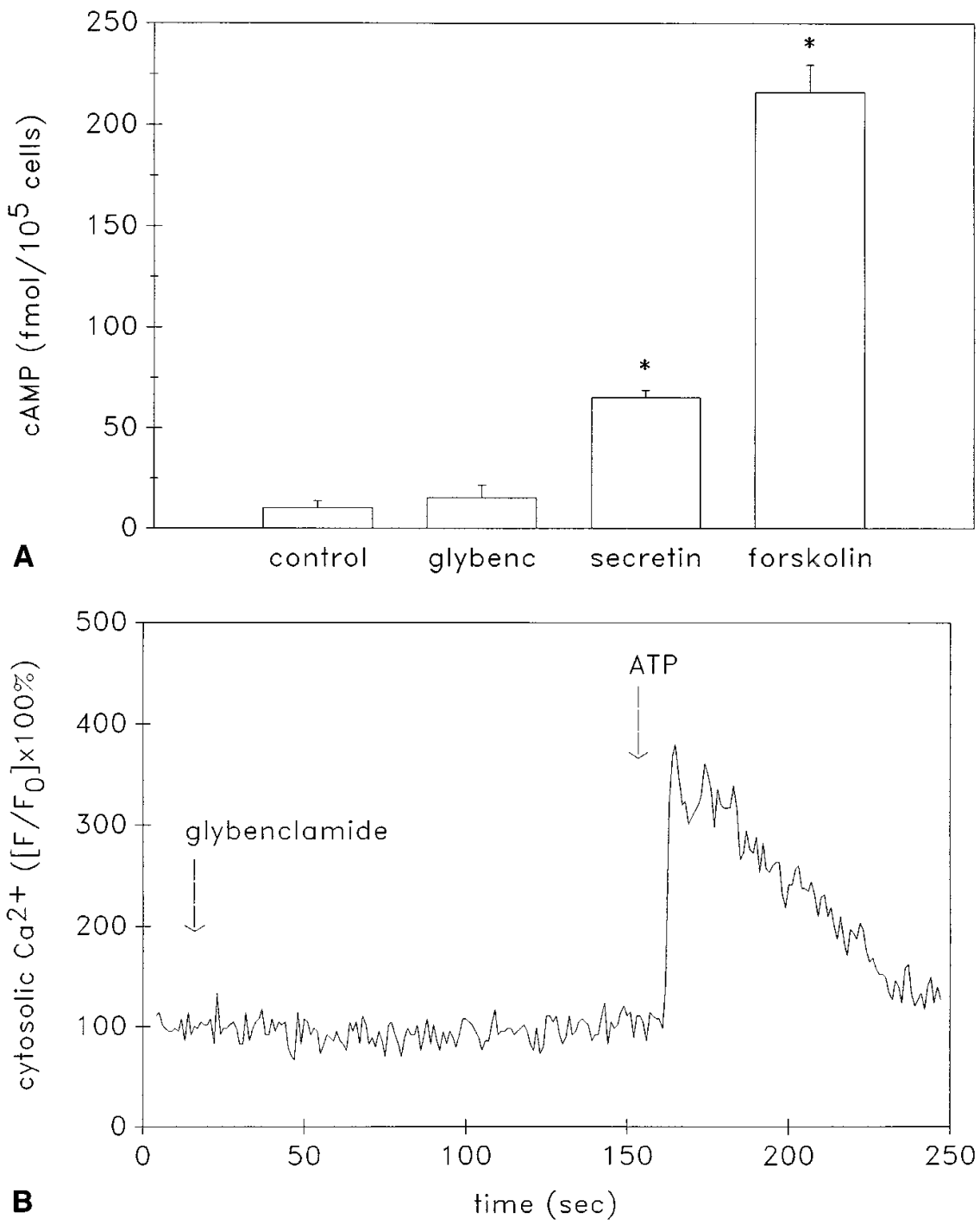

Figure 4. Glybenclamide does not activate second messengers in bile duct cells. $(A)$ Glybenclamide does not increase cAMP in bile duct epithelial cells. Cyclic AMP was measured by radioimmunoassay in freshly isolated bile duct cells that were unstimulated (controls) or stimulated with either $100 \mu \mathrm{M}$ glybenclamide, $100 \mathrm{nM}$ secretin, or $100 \mu \mathrm{M}$ forskolin. Secretin and forskolin but not glybenclamide increased cAMP in the cells. Values reflect mean $\pm \mathrm{SD}$ of $n=5$ measurements under each condition $(* P<0.001$ by ANOVA followed by Bonferroni post-tests). (B) Glybenclamide does not increase $\mathrm{Ca}_{\mathrm{i}}^{2+}$ in isolated bile duct units. Tracing reflects percent increase in fluorescence $\mathrm{F}$ of the $\mathrm{Ca}^{2+}$-sensitive dye fluo-3 (relative to initial fluorescence, $F_{0}$ ) in a bile duct cell within an isolated bile duct unit stimulated first with $100 \mu \mathrm{M}$ glybenclamide, then with the positive control, $10 \mu \mathrm{M}$ ATP. Results are representative of those seen in each of $n=13$ experiments. exchange, $\mathrm{Na}^{+}-\mathrm{HCO}_{3}^{-}$cotransport, $\mathrm{Cl}^{-}-\mathrm{HCO}_{3}^{-}$exchange, and $\mathrm{Na}^{+}-\mathrm{K}^{+}-2 \mathrm{Cl}^{-}$cotransport by monitoring $\mathrm{pH}$ changes in isolated bile duct units $(10,16)$ in response to maneuvers designed to examine the activities of each of these transporters.
Glybenclamide caused a rapid, reversible decrease in $\mathrm{pH}$ in bile duct cells (Fig. 6 A) $1 \mathrm{mM}$ amiloride blocks $\mathrm{Na}^{+}-\mathrm{H}^{+}$exchange $(15,31)$ but did not inhibit the proton flux, $\mathrm{JH}^{+}$, observed as glybenclamide was removed (Table I), suggesting

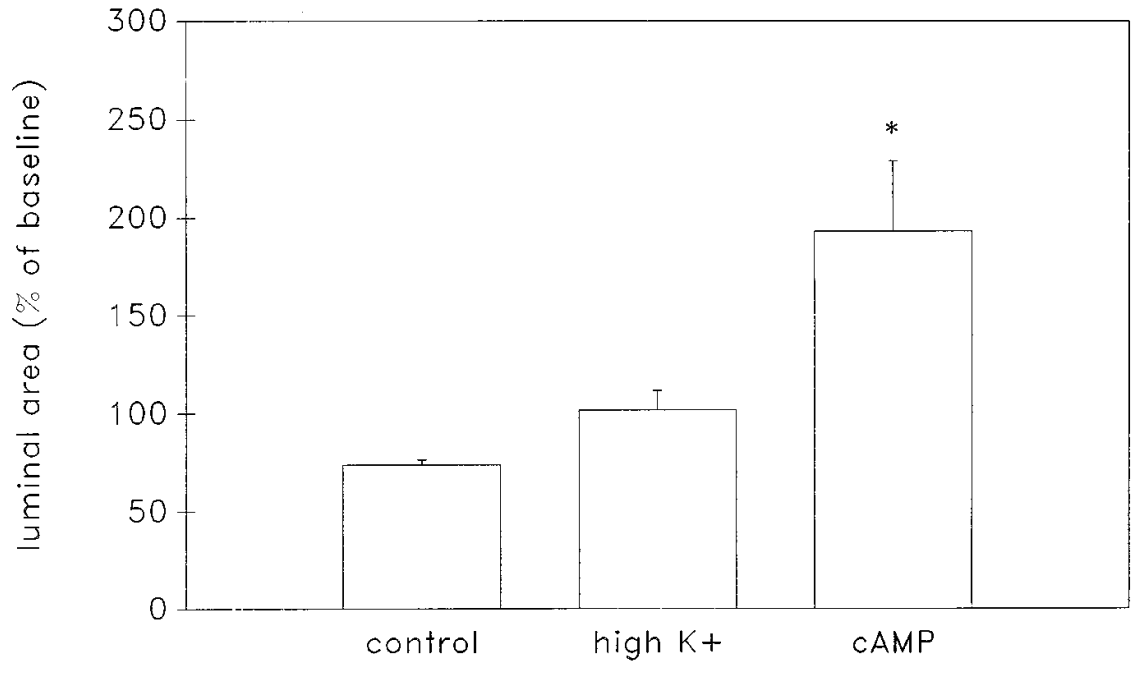

Figure 5. Depolarizing concentrations of extracellular $\mathrm{K}^{+}(40 \mathrm{mM})$ do not stimulate secretion in isolated bile duct units. A significant increase in the cross-sectional area of the lumen was seen in duct units stimulated with $50 \mu \mathrm{M}$ dibutyryl cAMP for 30 min but not in unstimulated (control) duct units or in duct units placed in high $\mathrm{K}^{+}$-medium for $30 \mathrm{~min}\left({ }^{*} \mathrm{P}<\right.$ 0.02 relative to both controls and high $\mathrm{K}^{+}$ group by ANOVA followed by Bonferroni post-tests; $P>0.35$ for high $\mathrm{K}^{+}$group vs. controls). Values represent mean \pm SEM of $n=7$ control duct units, $n=11 \mathrm{~K}^{+}$-treated units, and $n=9$ units treated with the cAMP analog. 

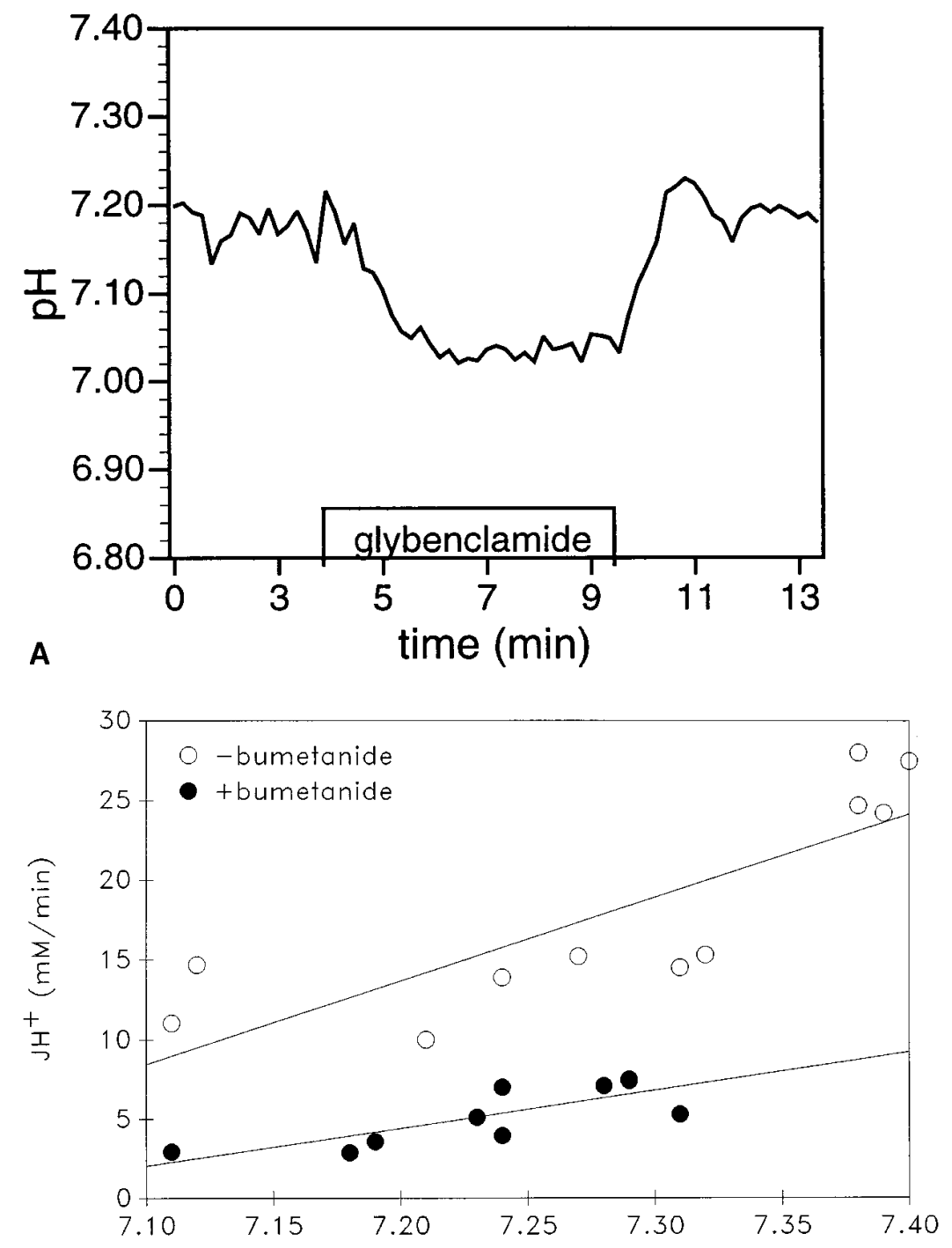

B

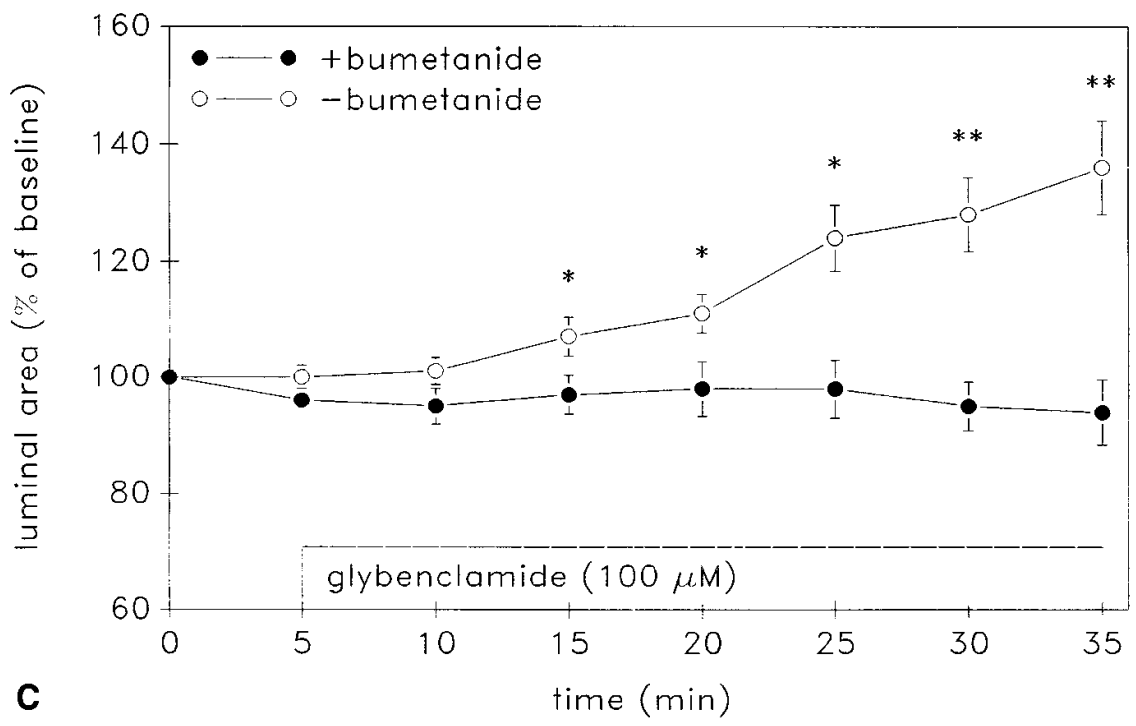

Figure 6. Glybenclamide acidifies bile duct cells in a bumetanide-sensitive fashion. $(A)$ Glybenclamide reversibly acidifies the cytosol of bile duct cells. Cytosolic pH was measured in individual bile duct cells within isolated bile duct units by ratio microspectrofluorimetry. Tracing is representative of that seen in 38 regions within 17 different isolated bile duct units. $(B)$ The $\mathrm{Na}^{+}-\mathrm{K}^{+}-2 \mathrm{Cl}^{-}$cotransport inhibitor bumetanide $(50 \mu \mathrm{M})$ retards glybenclamide's effects on cytosolic $\mathrm{pH}$. Glybenclamide increases $\mathrm{JH}^{+}$in direct proportion to cytosolic $\mathrm{pH}$, both in the absence (open circles; $r=0.825$ and $P<0.001$ for linear regression curve shown) and presence (closed circles; $r=0.791$ and $P<0.005$ for linear regression curve shown) of bumetanide. However, bumetanide significantly alters the relationship between $\mathrm{JH}^{+}$and $\mathrm{pH}\left(P<0.00001\right.$ by Hotelling's $T^{2}$ test) in an inhibitory fashion. No such change was seen with amiloride or DIDS (Table I). Measurements of $\mathrm{JH}^{+}$were made at the onset of the $\mathrm{pH}$ recovery that occurred as glybenclamide was withdrawn. (C) $50 \mu \mathrm{M}$ bumetanide blocks glybenclamide-induced secretion in isolated bile duct units. Cross-sectional area of the lumen increases progressively over time in bile duct units stimulated with glybenclamide (open circles, $n=9$ ), but this effect is blocked by bumetanide (closed circles, $n=13$ ). Values are mean $\pm \operatorname{SEM}(* P<0.05, * * P<0.0001)$. 


\begin{tabular}{|c|c|c|c|c|c|c|c|}
\hline \multirow[b]{2}{*}{ Inhibitor } & \multicolumn{2}{|c|}{ Glybenclamide + inhibitor } & \multirow[b]{2}{*}{$n$} & \multicolumn{3}{|c|}{ Glybenclamide alone (control group) } & \multirow[b]{2}{*}{$P$} \\
\hline & $\mathrm{JH}^{+}(\mathrm{mM} / \mathrm{min})$ & Cystolic pH & & $\mathrm{JH}^{+}(\mathrm{mM} / \mathrm{min})$ & Cystolic pH & $n$ & \\
\hline Amiloride & $3.57 \pm 1.49$ & $7.00 \pm 0.10$ & 8 & $5.11 \pm 2.43$ & $7.10 \pm 0.04$ & 9 & NS \\
\hline DIDS & $4.81 \pm 1.09$ & $7.05 \pm 0.04$ & 10 & $4.10 \pm 1.11$ & $7.11 \pm 0.13$ & 10 & NS \\
\hline Bumetanide & $5.29 \pm 1.88$ & $7.24 \pm 0.06$ & 10 & $18.09 \pm 6.63$ & $7.28 \pm 0.10$ & 11 & $<0.0001$ \\
\hline
\end{tabular}

*Values listed in this table are mean $\pm \mathrm{SD}$, and $P$ values refer to comparisons of $\mathrm{JH}^{+}$in the presence and absence of inhibitor. The pH is decreased significantly in the amiloride-treated group $(P<0.01)$, but not in the DIDS- or bumetanide-treated groups relative to their controls. Note that the average $\mathrm{pH}$ in the bumetanide controls is greater than in the amiloride or DIDS controls, but $\mathrm{pH}-\mathrm{JH}^{+}$data pairs from the three groups can be described by the same line $(r=0.788, P<0.00001)$, so that the relationship between $\mathrm{pH}$ and $\mathrm{JH}^{+}$is the same in each of these control groups.

that the effects of glybenclamide are independent of this exchanger. Similarly, both the $\mathrm{Cl}^{-}-\mathrm{HCO}_{3}^{-}$exchanger and the electrogenic $\mathrm{Na}^{+}-\mathrm{HCO}_{3}^{-}$cotransporter are blocked by the stilbene DIDS $(15,31)$, but $500 \mu \mathrm{M}$ DIDS did not alter $\mathrm{JH}^{+}$ during removal of glybenclamide (Table I), suggesting that glybenclamide does not act by modulating either of these $\mathrm{HCO}_{3}^{-}$transport systems. However, $50 \mu \mathrm{M}$ bumetanide blocks the $\mathrm{Na}^{+}-\mathrm{K}^{+}-2 \mathrm{Cl}^{-}$cotransporter $(27,31)$ and significantly decreased the effect of glybenclamide on $\mathrm{JH}^{+}(P<$ 0.00001; Fig. $6 B$ and Table I), suggesting that glybenclamide acts on this cotransporter. To determine whether bumetanidesensitive acidification of bile duct cells by glybenclamide is associated with secretion, we examined the effects of bumetanide on glybenclamide-induced secretion in isolated bile duct units (Fig. $6 \mathrm{C}$ ), and found that bumetanide abolished secretion $(P<0.0001)$. These findings suggest that glybenclamide specifically activates $\mathrm{Na}^{+}-\mathrm{K}^{+}-2 \mathrm{Cl}^{-}$cotransport in bile duct cells. This action in turn could account for both the acidifying and secretory effect of glybenclamide, since increased $\mathrm{Na}^{+}$ loading would secondarily inhibit both $\mathrm{Na}^{+}-\mathrm{H}^{+}$exchange and $\mathrm{Na}^{+}-\mathrm{HCO}_{3}^{-}$cotransport, leading to acidification of the cytosol, while increased $\mathrm{Cl}^{-}$loading by the cotransporter would enhance secretion through apical $\mathrm{Cl}^{-}$channels. Apical $\mathrm{Cl}^{-}$secretion generally is coupled to $\mathrm{Cl}^{-}-\mathrm{HCO}_{3}^{-}$exchange (7), which would account for the increased biliary $\mathrm{HCO}_{3}^{-}$excretion that is observed as well. In fact, we found that glybenclamide stimulated secretion by isolated bile duct units even in $\mathrm{HCO}_{3}^{-}$-free medium (Fig. 7), which further suggests that $\mathrm{HCO}_{3}^{-}$excretion is a secondary event.

Glybenclamide stimulates bile flow in cholestasis. To investigate whether the choleretic effect of glybenclamide is preserved in conditions of impaired bile secretion, we examined bile flow in perfused livers isolated from rats treated acutely with endotoxin or chronically with estrogen. Endotoxin- and estrogen-treated rats were used because these represent two well-established animal models of cholestasis in humans (17, 18). Baseline bile flow was impaired in livers from both endotoxin-treated and estrogen-treated animals (Fig. 8, $A$ and $B$, respectively). Glybenclamide increased bile flow by $40 \%(P<$ 0.05 ) in the livers of endotoxin-treated animals (Fig. $8 a$ ), and by $76 \%(P<0.02)$ in the livers of estrogen-treated animals (Fig. $8 \mathrm{~B}$ ). Glybenclamide also increased biliary $\mathrm{HCO}_{3}^{-}$concentration in both groups (Fig. 9). These findings demonstrate that glybenclamide retains its stimulatory effects on bile flow and biliary $\mathrm{HCO}_{3}^{-}$excretion, even in various types of cholestatic disorders. To investigate the mechanism whereby glybenclamide stimulates bile flow in these animals, we examined the effect of bumetanide on this glybenclamide-induced

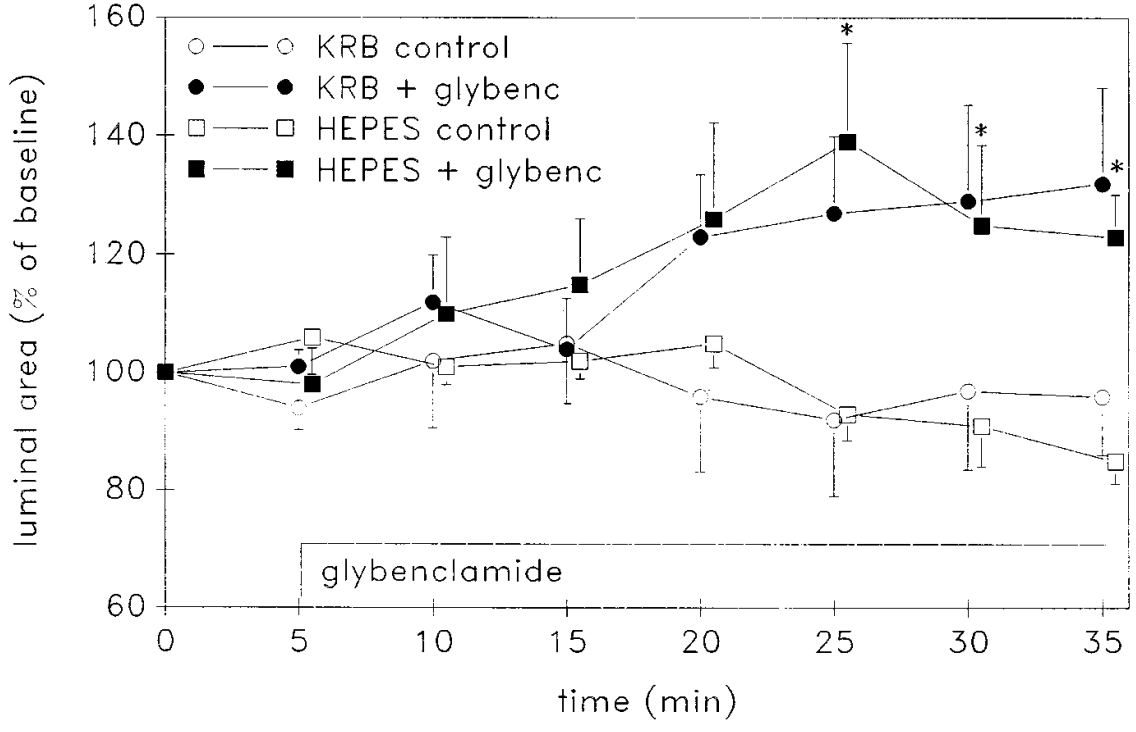

Figure 7. Glybenclamide stimulates secretion in $\mathrm{HCO}_{3}^{-}$-free medium in isolated bile duct units. $100 \mu \mathrm{M}$ glybenclamide induced similar increases in cross-sectional area of the lumen in duct units perifused with either $\mathrm{HCO}_{3}^{-}$-containing KRB buffer or $\mathrm{HCO}_{3}^{-}$-free Hepes buffer $\left({ }^{*} P<0.025\right.$ relative to unstimulated controls). Values represent mean \pm SEM of $n=4 \mathrm{KRB}$ controls, $n=6 \mathrm{Hepes}$ controls, $n=5$ units treated with glybenclamide in $\mathrm{KRB}$, and $n=6$ units treated with glybenclamide in Hepes. 

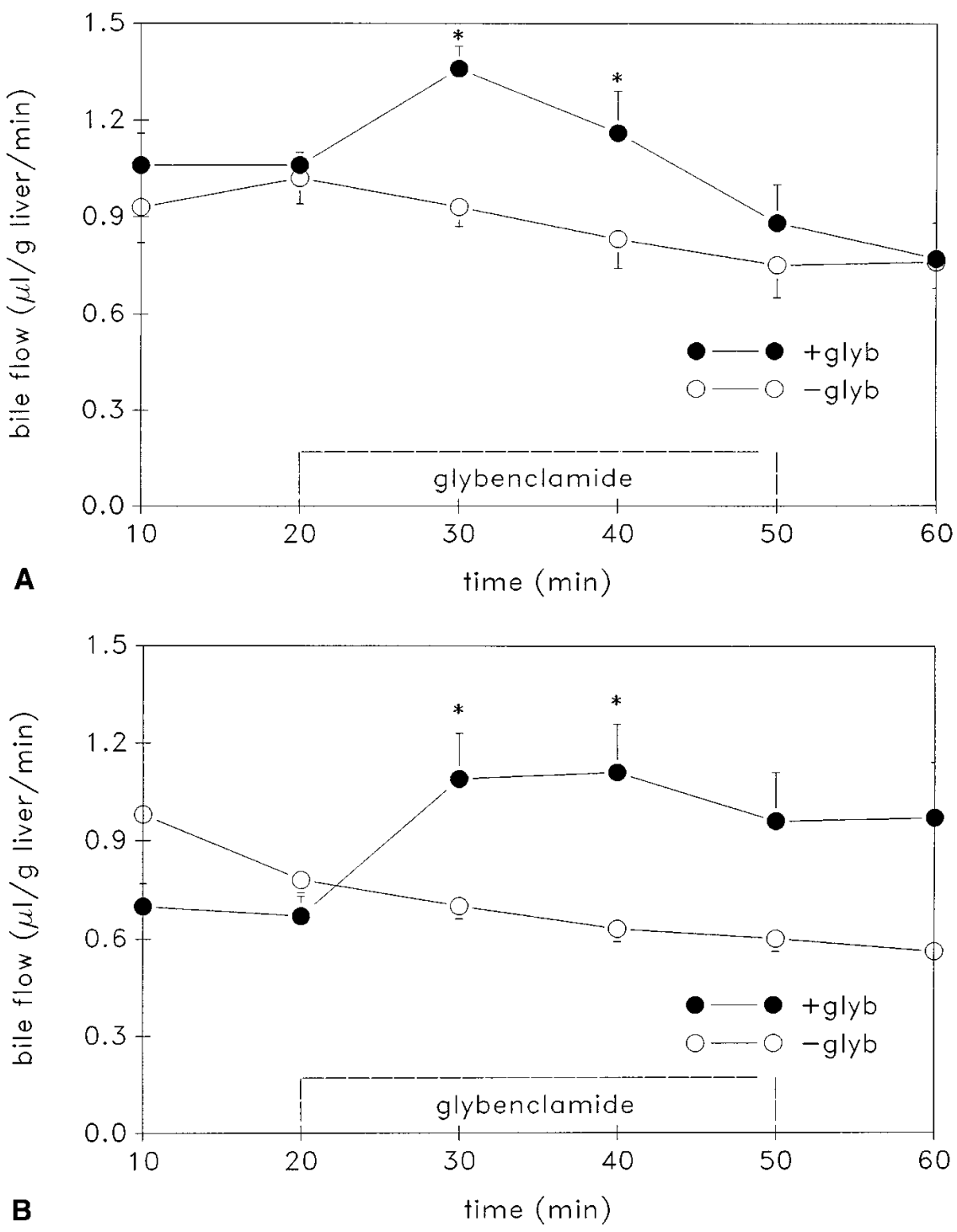

Figure 8. Glybenclamide stimulates bile flow in animal models of cholestasis. ( $A$ ) Glybenclamide stimulates bile flow in perfused rat livers isolated from endotoxin-treated rats. Bile flow is significantly increased $(* P<0.05)$ in glybenclamide-treated livers (closed circles; $n=5$ ) relative to untreated controls (open circles; $n=4)$. (B) Glybenclamide stimulates bile flow in perfused rat livers isolated from estrogen-treated rats. Bile flow is significantly increased $(* P<0.05)$ in glybenclamide-treated livers (closed circles; $n=6$ ) relative to untreated controls (open circles; $n=4$ ). choleresis. $50 \mu \mathrm{M}$ bumetanide completely abolished the choleretic effect of glybenclamide in livers of endotoxintreated animals $(P=0.001)$, and reduced the choleretic effect by $62 \%(P=0.03)$ in livers of estrogen-treated animals (Fig. 10). These findings suggest that glybenclamide stimulates bile flow by activation of $\mathrm{Na}^{+}-\mathrm{K}^{+}-2 \mathrm{Cl}^{-}$cotransport, even in animal models of cholestasis.

\section{Discussion}

Here we report that the sulfonylurea glybenclamide stimulates bile flow in the isolated perfused rat liver. Glybenclamide increased bile flow by $>50 \%$ at a concentration of only $10 \mu \mathrm{M}$, suggesting that this increase in secretion is not merely an osmotic effect. To put the magnitude of this choleresis into perspective, $50 \mu \mathrm{M}$ tauroursodeoxycholic acid (to which the therapeutic bile acid ursodiol is rapidly converted in vivo [32]) increases bile flow by only $32 \%$ in the same experimental system (Nathanson, M.H., unpublished observations). Chemical analysis of the bile demonstrated that glybenclamide also stimulates biliary excretion of $\mathrm{HCO}_{3}^{-}$, which likely serves as the major driving force for the increase in bile flow. To understand the cellular basis for this choleresis, secretion was examined in preparations of the two epithelia that contribute to bile formation, hepatocytes and bile duct cells (20). These isolated cell studies demonstrated that glybenclamide stimulates secretion in bile duct cells but not in hepatocytes. This finding is consistent with our observations in the perfused liver for the following reasons. If the effect of glybenclamide on secretion was either osmotic or due to increased excretion of glutathione or glutathione conjugates, then this should have resulted primarily in increased secretion by hepatocyte couplets (20) rather than by bile duct units. However, $\mathrm{HCO}_{3}^{-}$can be excreted in a regulated fashion by either hepatocytes $(20,33)$ or bile duct cells $(6,7,10,25)$. Thus, our studies in the whole organ and in single cells together suggest that glybenclamide specifically stimulates secretion by bile duct epithelial cells, which markedly increases total bile flow and $\mathrm{HCO}_{3}^{-}$excretion.

The understanding of bile duct cell physiology, especially as it relates to secretion, has been very limited until recently. New techniques to isolate bile duct cells and bile duct segments $(10,34,35)$, along with the development of polarized 


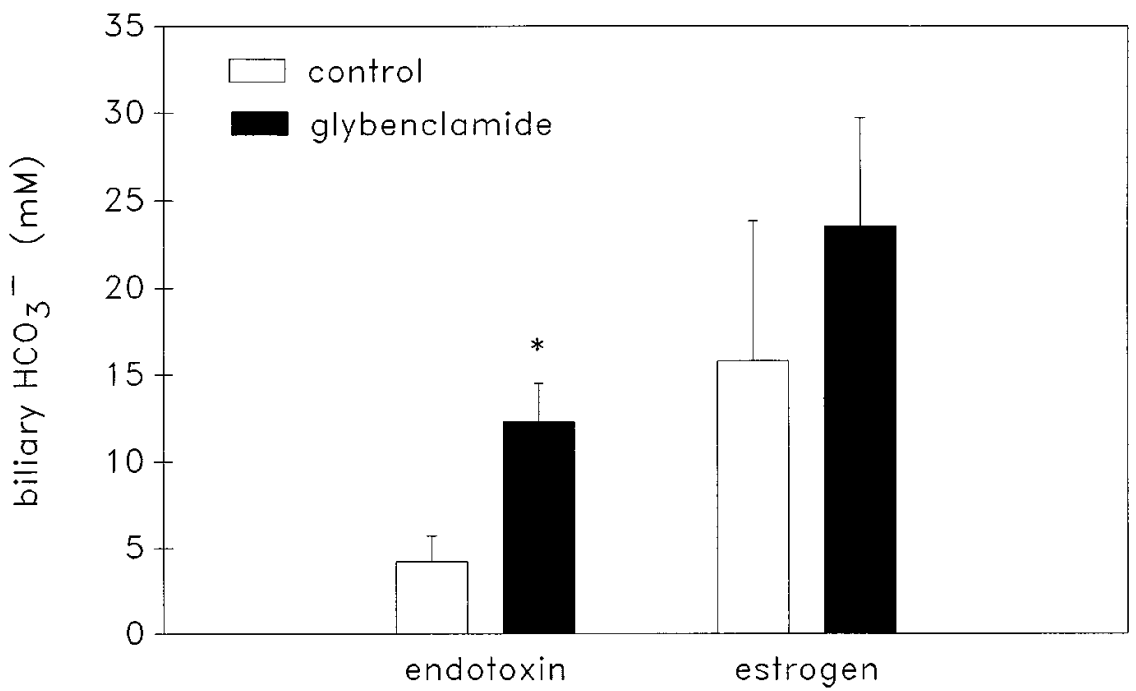

Figure 9. Glybenclamide (closed bars) stimulates $\mathrm{HCO}_{3}^{-}$excretion in isolated perfused livers from endotoxin- and estrogen-treated rats, relative to untreated controls (open bars). The increase in biliary $\mathrm{HCO}_{3}^{-}$concentration is significant $(* P=0.01)$ in endotoxin-treated but not in estrogen-treated livers. Note that in normal livers (Fig. 1), the response to glybenclamide was compared to the baseline (preglybenclamide) response, whereas here the glybenclamide response is compared with the response in untreated controls, since bile flow decreases much more quickly over time in the cholestatic livers. bile duct cell lines (36), have permitted the principal pathways and transporters involved in ductal secretion to be identified $(6,7)$. The current study has taken advantage of these advances to demonstrate that glybenclamide stimulates secretion by bile duct epithelial cells, and to determine that this stimulation results from activation of the $\mathrm{Na}^{+}-\mathrm{K}^{+}-2 \mathrm{Cl}^{-}$cotransporter recently identified in this cell type $(26,27)$. This particular transporter plays a major role in regulating secretion in many polarized epithelia (31). This study demonstrates the extent to which this transporter can stimulate secretion in bile duct cells in particular, and furthermore suggests that activity of this transporter can be increased by pharmacologic means to stimulate net secretion by the whole organ. This finding is particularly unexpected because it previously was believed that maximal stimulation of ductular secretion in normal livers would only increase net bile flow by $\sim 10 \%$ (20). This work suggests instead that net bile flow in normal livers can be doubled by maximal stimulation of ductular secretion with glybenclamide. Thus, bile duct cells appear able to contribute to net bile secretion to a much more significant degree than previously appreciated.
The mechanism of action of glybenclamide in this study appears to be novel. Glybenclamide is widely used to treat type II diabetes, since it binds to the sulfonylurea receptor of pancreatic $\beta$ cells, which in turn inhibits associated $\mathrm{K}^{+}$channels (29). This leads to depolarization of the $\beta$ cell, which triggers voltage-gated $\mathrm{Ca}^{2+}$ channels, thus increasing $\mathrm{Ca}_{\mathrm{i}}^{2+}$ and stimulating insulin secretion (29). This mechanism of action does not appear to operate in bile duct cells, since glybenclamide failed to increase $\mathrm{Ca}_{\mathrm{i}}^{2+}$ in these cells and since depolarization via high $\mathrm{K}^{+}$-medium failed to stimulate secretion. Glybenclamide also may block ATP secretion via ATP binding cassette protein transporters such as CFTR and mdr1 (37), but this putative action is unlikely to account for the effect seen in bile duct cells, either. ATP is present in bile (38), where it stimulates biliary $\mathrm{Cl}^{-}$ secretion by activation of apical $\mathrm{P}_{2 \mathrm{U}}$ receptors (24). Therefore, inhibition of ATP transport into bile would be expected to decrease rather than increase ductular secretion. In addition, there is no change in biliary ATP in livers treated with glybenclamide (Nathanson, M.H., unpublished observation). We are unaware of other cell systems in which glybenclamide has been found to directly activate either $\mathrm{Na}^{+}-\mathrm{K}^{+}-2 \mathrm{Cl}^{-}$cotransport or any other

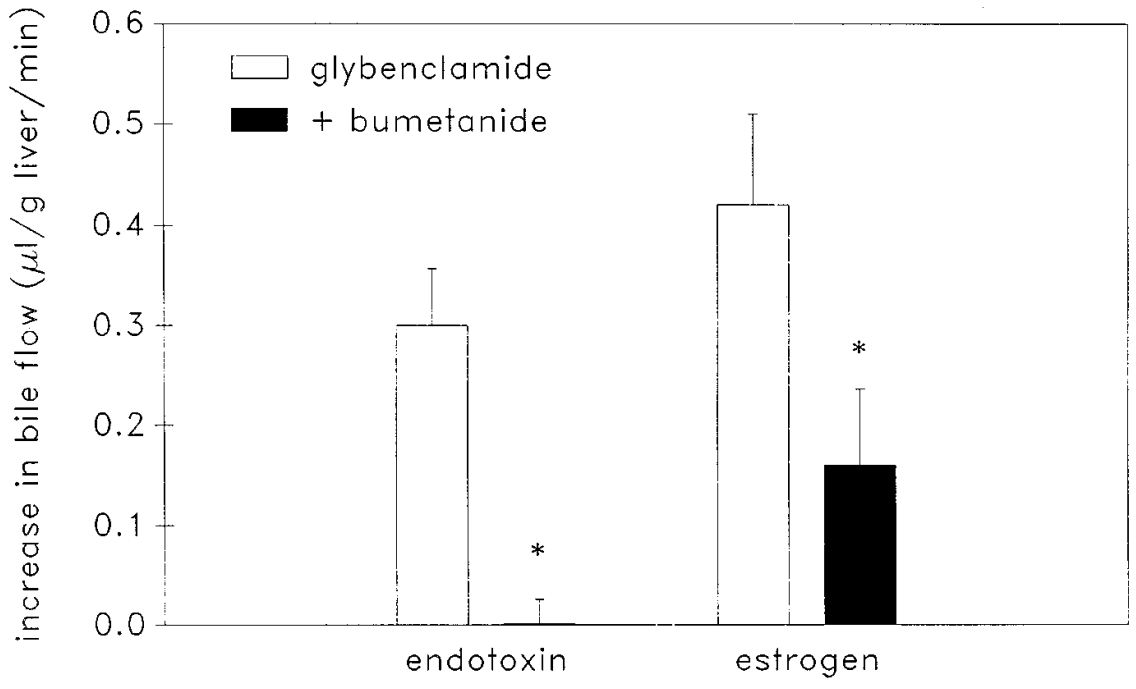

Figure 10. Bumetanide blocks the stimulatory effect of glybenclamide on bile flow in isolated perfused livers from endotoxin- and estrogentreated rats. The change in bile flow relative to baseline was measured after $10 \mathrm{~min}$ of $100 \mu \mathrm{M}$ glybenclamide $\pm 50 \mu \mathrm{M}$ bumetanide. The increase in bile flow induced by glybenclamide alone was significantly higher than the increase induced by glybenclamide plus bumetanide, both in livers from endotoxin-treated $(n=5$ and 4 , respectively; $* P<0.05$ ) and estrogentreated $(n=6$ and 5 , respectively; $* P<0.05)$ rats. 
ion transporter. Further studies will be needed to clarify the mechanism whereby glybenclamide activates biliary $\mathrm{Na}^{+}-\mathrm{K}^{+}-$ $2 \mathrm{Cl}^{-}$cotransport, and to determine if this transporter is similarly activated by glybenclamide in other tissues in which it is expressed.

This study demonstrates that the choleretic action of glybenclamide is bumetanide sensitive, and that this action is maintained in livers from endotoxin- and estrogen-treated rats, which are models for the cholestasis of sepsis and druginduced cholestasis, respectively $(17,18)$. This finding suggests that the molecular mechanism whereby glybenclamide stimulates bile flow may be useful for the treatment of cholestatic disorders. Whether glybenclamide itself would be useful to treat cholestasis is unclear. Peak serum levels of glybenclamide after a 3.5 -mg oral dose are $\sim 1 \mu \mathrm{M}$ in humans $(39,40)$, which is significantly less than the $K_{\mathrm{d}}$ of $9.5 \mu \mathrm{M}$ observed in the current study. However, after gut absorption of glybenclamide, the drug is avidly removed from the portal circulation by the liver, then subjected to enterohepatic recirculation $(39,40)$. Therefore, cholangiocytes in vivo may be exposed to a much higher concentration of glybenclamide than would be reflected by a serum concentration of $1 \mu \mathrm{M}$. Currently, the only treatment for cholestasis that is of proven benefit is ursodiol (2). The mechanism whereby ursodiol exerts its beneficial effect is not established, but it may in part result from ursodiol displacing more toxic bile acids from the endogenous bile acid pool (41). This could account for the observations that ursodiol often slows the progression of certain cholestatic disorders, rather than inducing actual clinical improvement, and that months to years of treatment are required in any case before a beneficial effect is seen $(3,42)$. Since many cholestatic disorders are the result of biliary dysfunction (6), a rational and perhaps more effective treatment strategy would be to directly stimulate secretion by bile duct cells. Although treatments for such disorders have not yet been directed towards these cells, the current work suggests that it may be practical to selectively stimulate bile ductular secretion, and that this treatment approach would improve bile flow in cholestasis.

\section{Acknowledgments}

We thank James L. Boyer, Michael Trauner, and Satish K. Singh for useful discussions, Domenico Alvaro for help with $\mathrm{pH}$ calculations, and Michelle K. Pate for assistance with cell isolations.

This work was supported by a grant from the National Institutes of Health (DK-45710) and by the Morphology, Liver Perfusion, and Cell Isolation Core Facilities of the Yale Liver Center (DK-34989).

\section{References}

1. Pasha, T.M., and K.D. Lindor. 1996. Diagnosis and therapy of cholestatic liver disease. Med. Clin. N. Am. 80:995-1019.

2. Ramirez, R.O., and R.J. Sokol. 1994. Medical management of cholestasis. In Liver Disease in Children. F.J. Suchy, editor. C.V. Mosby and Co., St. Louis, MO. 356-388.

3. Poupon, R.E., R. Poupon, and B. Balkau. 1994. Ursodiol for the longterm treatment of primary biliary cirrhosis. N. Engl. J. Med. 330:1342-1347.

4. Beuers, U., U. Spengler, W. Kruis, U. Aydemir, B. Wiebecke, W. Heldwein, M. Weinzierl, G.R. Pape, T. Sauerbruch, and G. Paumgartner. 1992. Ursodeoxycholic acid for treatment of primary sclerosing cholangitis: a placebocontrolled trial. Hepatology. 16:707-714.

5. Colombo, C., P.M. Battezzati, M. Podda, N. Bettinardi, and A. Giunta. 1996. Ursodeoxycholic acid for liver disease associated with cystic fibrosis: a double-blind multicenter trial. Hepatology. 23:1484-1490.

6. Roberts, S.K., J. Ludwig, and N.F. LaRusso. 1997. The pathobiology of biliary epithelia. Gastroenterology. 112:269-279.
7. Boyer, J.L. 1996. Bile duct epithelium: frontiers in transport physiology. Am. J. Physiol. (Gastrointest. Liver Physiol.). 270:G1-G5.

8. Nathanson, M.H., A. Gautam, R. Bruck, C.M. Isales, and J.L. Boyer. 1992. Effects of $\mathrm{Ca}^{2+}$ agonists on cytosolic $\mathrm{Ca}^{2+}$ in isolated hepatocytes and on bile secretion in the isolated perfused rat liver. Hepatology. 15:107-116.

9. Bruck, R., M.H. Nathanson, H. Roelofsen, and J.L. Boyer. 1994. Effects of protein kinase $\mathrm{C}$ and cytosolic $\mathrm{Ca}^{2+}$ on exocytosis in the isolated perfused rat liver. Hepatology. 20:1032-1040.

10. Mennone, A., D. Alvaro, W. Cho, and J.L. Boyer. 1995. Isolation of small polarized bile duct units. Proc. Natl. Acad. Sci. USA. 92:6527-6531.

11. Nathanson, M.H., A.D. Burgstahler, A. Mennone, and J.L. Boyer. 1996. Characterization of cytosolic $\mathrm{Ca}^{2+}$ signaling in rat bile duct epithelia. Am. J. Physiol. (Gastrointest. Liver Physiol.). 271:G86-G96.

12. Graf, J., A. Gautam, and J.L. Boyer. 1984. Isolated rat hepatocyte couplets: a primary secretory unit for electrophysiologic studies of bile secretory function. Proc. Natl. Acad. Sci. USA. 81:6516-6520.

13. Gautam, A., O.C. Ng, M. Strazzabosco, and J.L. Boyer. 1989. Quantitative assessment of canalicular bile formation in isolated hepatocyte couplets using microscopic optical planimetry. J. Clin. Invest. 83:565-573.

14. Burgstahler, A.D., and M.H. Nathanson. 1995. NO modulates the apicolateral cytoskeleton of isolated hepatocytes by a PKC-dependent, cGMP-independent mechanism. Am. J. Physiol. (Gastrointest. Liver Physiol.). 269:G789G799.

15. Strazzabosco, M., A. Mennone, and J.L. Boyer. 1991. Intracellular pH regulation in isolated rat bile duct epithelial cells. J. Clin. Invest. 87:1503-1512.

16. Alvaro, D., G. Alpini, A.M. Jezequel, C. Bassotti, C. Francia, F. Fraioli, R. Romeo, L. Marucci, G. LeSage, S.S. Glaser, and A. Benedetti. 1997. Role and mechanisms of action of acetylcholine in the regulation of rat cholangiocyte secretory function. J. Clin. Invest. 100:1349-1362.

17. Trauner, M., M.H. Nathanson, S.A. Rydberg, T.A. Koeppel, C. Gartung, W.C. Sessa, and J.L. Boyer. 1997. Endotoxin impairs biliary glutathione and $\mathrm{HCO}_{3}^{-}$excretion and blocks the choleretic effect of nitric oxide in rat liver. Hepatology. 25:1184-1191.

18. Trauner, M., M. Arrese, C.J. Soroka, M. Ananthanarayanan, T.A. Koeppel, S.F. Schlosser, F.J. Suchy, D. Keppler, and J.L. Boyer. 1997. The rat canalicular conjugate export pump (mrp2) is down-regulated in intrahepatic and obstructive cholestasis. Gastroenterology. 113:255-264.

19. Erlinger, S. 1994. Bile flow. In The Liver: Biology and Pathobiology. I.M. Arias, J.L. Boyer, N. Fausto, W.B. Jakoby, D.A. Schachter, and D.A. Shafritz, editors. Raven Press, New York. 769-786.

20. Nathanson, M.H., and J.L. Boyer. 1991. Mechanisms and regulation of bile secretion. Hepatology. 14:551-566.

21. Boyer, J.L., and C.J. Soroka. 1995. Vesicle targeting to the apical domain regulates bile excretory function in isolated rat hepatocyte couplets. Gastroenterology. 109:1600-1611.

22. Cohn, J.A., T.V. Strong, M.R. Picciotto, A.C. Nairn, F.S. Collins, and J.G. Fitz. 1993. Localization of the cystic fibrosis transmembrane conductance regulator in human bile duct epithelial cells. Gastroenterology. 105:1857-1864.

23. Fitz, J.G., S. Basavappa, J. McGill, O. Melhus, and J.A. Cohn. 1993. Regulation of membrane chloride currents in rat bile duct epithelial cells. $J$. Clin. Invest. 91:319-328.

24. Schlenker, T., J. Romac, A.I. Sharara, R.M. Roman, S. Kim, N.F. LaRusso, R. Liddle, and J.G. Fitz. 1997. Regulation of biliary secretion through apical purinergic receptors in cultured rat cholangiocytes. Am. J. Physiol. (Gastrointest. Liver Physiol.). 273:G1108-G1117.

25. Alvaro, D., W.K. Cho, A. Mennone, and J.L. Boyer. 1993. Effect of secretin on intracellular $\mathrm{pH}$ regulation in isolated rat bile duct epithelial cells. $J$. Clin. Invest. 92:1314-1325.

26. Basavappa, S., J. Middleton, A.W. Mangel, J.M. McGill, J.A. Cohn, and J.G. Fitz. 1993. $\mathrm{Cl}^{-}$and $\mathrm{K}^{+}$transport in human biliary cell lines. Gastroenterology. 104:1796-1805.

27. Singh, S.K., A. Mennone, and J.L. Boyer. 1996. Na-K-2Cl cotransport participates in stimulated fluid secretion in isolated polarized bile duct units from rat liver. Hepatology. 24:148a. (Abstr.).

28. Nelson, T.Y., K.L. Gaines, A.S. Rajan, M. Berg, and A.E. Boyd. 1987. Increased cytosolic calcium. A signal for sulfonylurea-stimulated insulin release from beta cells. J. Biol. Chem. 262:2608-2612.

29. Garcia-Barrado, M.J., J.C. Jonas, P. Gilon, and J.C. Henquin. 1996. Sulphonylureas do not increase insulin secretion by a mechanism other than a rise in cytoplasmic Ca2+ in pancreatic B-cells. Eur. J. Pharmacol. 298:279-286.

30. Roman, R.M., Y. Wang, and J.G. Fitz. 1996. Regulation of cell volume in a human biliary cell line: Activation of $\mathrm{K}^{+}$and $\mathrm{Cl}^{-}$currents. Am. J. Physiol. (Gastrointest. Liver Physiol.). 271:G239-G248.

31. Kaplan, M.R., D.B. Mount, and E. Delpire. 1996. Molecular mechanisms of NaCl cotransport. Annu. Rev. Physiol. 58:649-668.

32. Beuers, U., M.H. Nathanson, and J.L. Boyer. 1993. Effects of tauroursodeoxycholic acid on cytosolic $\mathrm{Ca}^{2+}$ signals in isolated rat hepatocytes. Gastroenterology. 104:604-612.

33. Benedetti, A., M. Strazzabosco, O.C. Ng, and J.L. Boyer. 1994. Regulation of activity and apical targeting of the $\mathrm{Cl}^{-} / \mathrm{HCO}_{3}^{-}$exchanger in rat hepatocytes. Proc. Natl. Acad. Sci. USA. 91:792-796.

34. Roberts, S.K., S.M. Kuntz, G.J. Gores, and N.F. LaRusso. 1993. Regula- 
tion of bicarbonate-dependent ductular bile secretion assessed by lumenal micropuncture of isolated rodent intrahepatic bile ducts. Proc. Natl. Acad. Sci. USA. 90:9080-9084.

35. Ishii, M., B. Vroman, and N.F. LaRusso. 1989. Isolation and morphologic characterization of bile duct epithelial cells from normal rat liver. Gastroenterology. 97:1236-1247.

36. Vroman, B., and N.F. LaRusso. 1996. Development and characterization of polarized primary cultures of rat intrahepatic bile duct epithelial cells. Lab. Invest. 74:303-313.

37. Al-Awqati, Q. 1995. Regulation of ion channels by ABC transporters that secrete ATP. Science. 269:805-806.

38. Chari, R.S., S.M. Schutz, J.E. Haebig, G.H. Shimokura, P.B. Cotton, J.G. Fitz, and W.C. Meyers. 1996. Adenosine nucleotides in bile. Am. J. Physiol. (Gastrointest. Liver Physiol.). 270:G246-G252.
39. Rydberg, T., A. Jonsson, and A. Melander. 1995. Comparison of the kinetics of glyburide and its active metabolites in humans. J. Clin. Pharmacol. Ther. 20:283-295.

40. Rydberg, T., A. Jonsson, M.O. Karlsson, and A. Melander. 1997. Concentration-effect relations of glibenclamide and its active metabolites in man: modelling of pharmacokinetics and pharmacodynamics. Br. J. Clin. Pharmacol. 43:373-381.

41. Hofmann, A.F. 1994. Bile acids. In The Liver: Biology and Pathobiology. I.M. Arias, J.L. Boyer, N. Fausto, W.B. Jakoby, D.A. Schachter, and D.A. Shafritz, editors. Raven Press, New York. 677-718.

42. Poupon, R.E., K.D. Lindor, K. Cauch-Dudek, E.R. Dickson, R. Poupon, and E.J. Heathcote. 1997. Combined analysis of randomized controlled trials of ursodeoxycholic acid in primary biliary cirrhosis. Gastroenterology. 113: 884-890. 